\title{
Experimenting the Feasibility of Banana Stalk for Practical Textile
}

\author{
Kenneth Bright Boateng, Bridgette Aidoo-Taylor, Sarah Archer \\ Takoradi Polytechnic, Takoradi, Ghana
}

\begin{abstract}
Finding viable alternatives to conventional textiles and fashion has proved to be a herculean challenge for government and policy makers in Ghana. Banana stalk identified as possible eccentric material for textiles and fashion needs to be examined to ascertain its feasibility. The study intends to engage mixed approach with particular emphasis on experimental methods to ascertain feasibility of banana stalk braids for textiles. Also what to be adopted are observation, descriptive, interpretative, and narrative methods. Test results from the study are necessary for determining the extent to which the materials could be applied for varying textiles and costumes. Adopting waste as alternative material in fashioning costumes for textile art and subsequently normal fashion for humans is a possible means to turn around the poorly performing the industrial sub-sector. It also has the potential of being converted into sacks for packaging some foodstuffs like grains, tubers, and cocoa. The success of this research shall pave way for looking inward the nation for readily available and relatively cheap materials for addressing the concern of local textiles and fashion.
\end{abstract}

Keywords: textiles, banana stalk, braid, alternative, and material

\section{Introduction}

Approaching the end of last Millennium, dynamism, resilience, and performance of Ghana's economy began to wane. Textile industrial sub-sector was one of the most affected; a situation that has not changed much after many direct and indirect government interventions. Basically, everything of textiles is imported with the exception of three companies do finishing of some woven cotton and polyester derivatives. Juapong Textile Ltd. does some limited spinning and weaving of cotton but the firm is not strong enough to challenge key global players. Amidst these challenges, growing need of textiles for clothing, packaging, textile art, and industrial furnishing continues to surge.

By and large, banana is a major staple in Ghana but does not attract national attention as cocoa and relatively expensive and becomes quite rare during dry seasons. Banana stalk originally was treated as waste looks to have the potential of getting drafted into conventional textiles. If successful, the outcome of the investigations launched should facilitate new breathe of life into textile technology in areas where Ghana has comparative strength. That coordinated cultivation of the crop will serve two purposes: providing food at

Kenneth Bright Boateng, Mr., Department of Fashion Design, Takoradi Polytechnic, Takoradi, Ghana. Bridgette Aidoo-Taylor, Ms., Department of Fashion Design, Takoradi Polytechnic, Takoradi, Ghana.

Sarah Archer, Ms., Department of Fashion Design, Takoradi Polytechnic, Takoradi, Ghana.

Correspondence concerning this article should be addressed to Kenneth Bright Boateng, Department of Fashion Design, Takoradi Polytechnic, P.O. Box TD 256, Takoradi, Ghana. 
reasonable prices throughout the year and providing basic material for alternative textiles for functions stated earlier. The advantage of alternative use will be made from the stalk which hitherto will be largely singed with some few applied as mulching. The excitement to be generated from successful outcome of the study should drive national efforts into sustainable and alternative textiles for local consumption and eventually global consumption. For instance, successful packaging of cocoa beans will virtually revolutionize the cocoa industry where most of the jute sack is imported. It is also the cocoa growing areas that banana is cultivation and is the most prominent in Ghana.

The paper thus seeks to ascertain the possibility of converting the banana stalk into practical textiles adopting broadly mixed approach where experimentation will feature prominently and be complemented with observation, descriptive, interpretative, and narrative research methods/design.

\section{Literature Review}

According to Linnenkoper (2016), Dag Benestad, head of dissolving pulp production at Sodra of Scandinavia, is noted to have remarked that cotton is expect to peak whiles, literal demand for textiles will keep on growing. In direct correlation, Boon (1981) opined alternative textile technologies to have experienced fast growth. Sufficing to say, global attention on alternative eco-friendly textiles happens to be the new order. Steph (2012) illustrated relying on polluting textile materials like cotton and polyester may become a thing of the past as a new range of eco-fabrics emerge, often made from materials that would otherwise go to waste. Similarly, banana stalk has been treated as waste in Ghana since introduction of the crop into the local economy. Actually, serving as food, no real alternative use has been made apart from packaging some indigenous food. Relatively, the once buoyant textile sub-industry employing $25 \%$ labour within the state then it has been wobbling (Quartey, 2006). In fact, it is obvious that for nearly 20 years, this particular industry has been underperforming grossly at its peak in 1975, the virtual 30 manufacturing firms have been reduced to virtually three which are struggling anyway (Quartey, 2006). At present, there appears to be no clear consented effort to delve into textile technology to reverse the trend. The most endowed academic institution-Kwame University for Science and Technology (KNUST) where textiles have been handled as a discipline for almost half a century is limited significantly in facilitating textile technology. Everything about fibres, yarns, and alternative textiles is import driven apart from one company Juapong Textiles Ltd. that spins and weaves cotton into grey baft in small quantities. In sum, Ghana's textiles are struggling to match up at grossly competitive global textile sub-sector.

Testing to ascertain the feasibility of banana braids is revolutionary for successful outcome of the study and should provide platform for alternative textiles. The new dimensional textiles have the potential to be adopted in textile art, apparel, accessories, and industrial packaging for items like cocoa, grains, beans, and tubers as concept of "Creative Arts and Sustainable Development" alludes. Essentially, readily available textiles that are cheap and every Ghanaian which has unrelated but highly vital purposes like food at relatively cheap cost for the economy of Ghana should be tremendously welcome news indeed. In that, banana is a major delicacy in Ghana, but it does not have national attention as cocoa. Getting coordinated cultivation of the crop for food, textiles should facilitate diversity and new impetus into textile technology as sustained and readily available materials should help generate new interest in the passive industrial sub-sector. Hopefully, the inquest should assist to create a niche in which the nation could have a comparative advantage as coined by Linnenkoper (2016), going into alternative textile technology will "revive 
their industry and meet demand from both fashion and furniture firms for alternative textiles to cotton". From the above, it is obvious that ultimate impact of the banana stalk, if successful, could be very exciting as interests from broad and varying options and diversity for household and industrial products. In support, sport shoes brands such as Puma and Camper, as well interior design, technology and other names from the fashion industry are using the newly launched PINATEX ${ }^{\mathrm{TM}}$ which employs pineapple leaves as fake leather for their products and prototypes (Hijosa, 2016). A close study with Carmen Hijosa's work with pineapple reveals dual purpose of supplying food and engendering textiles and leather from the bi-product: leaves just as the banana.

\section{Research Design}

Being an explorative study which was spontaneously initiated and delivered personally to satisfy curiosity and advance knowledge and technology in textiles and fashion, the project was based on self-generated structure. It formed part of inquest performed for MFA Textile Design in 2009 at KNUST. The core objectives of the research are directed making the braids practical for fashion and industrial use. Ensuring to have credible study with outcomes that are verifiable and valid, the following were engaged: experimentation, observation, descriptive, interpretative, and narrative designs have been employed in handling the variables reviewed. The relevance of the above is placed in relation with the fact that most of the work was executed in the studio. Firstly, the experimentation fundamentally dealt with studying to understand the nature and plausibility of the banana stalk, braids, and subsequent end use requiring close observation for a reasonable period of time. Thankfully, some of the tests were adopted from elsewhere as templates as the similar tests, analyses, and conclusions have already been achieved and would be irrelevant to go through the same laborious and expensive process of which the outcome is already known. The key reason why most of the tests for chemical structure and contents were extrapolated from previous studies was based on the fact that the forensic infrastructure in Ghana is still at the developmental stages and is not well-endowed to undertake all the studies being required.

Essence of utilizing qualitative approach became unquestionable, as observation, descriptive, interpretative, and narrative designs and methods were instituted in data gathering, analysis, and conclusion. With clear strategy and plan, the investigations took off.

\section{Analysis}

\section{Fibre Structure Analysis}

The effective performance of a fabric and apparel is dependent on the properties of the fibre. By this, a textile fibre from the beginning could aid in determining possible future uses before conversion into usable materials. Fibre structure analysis which has been explained by Textile Printing Market (2014), as fibre identification methods seek to basically determine the potential uses of textile fibres through the characteristics and properties as determined by the following factors: "Essential Characteristics", "Physical Structure", and "Chemical Structure".

\section{Essential Characteristics}

Textiles are usually developed from tiny molecular elements called fibres from which yarns (another tiny molecular element but larger in diameter than fibre) are made. According to Sourcing Materials (2014), some basic information about fibers and fabric specifications is essential for evaluating and comparing available 
materials. Essential characteristics are a textile terminology used to test the viability and applicability of a material to establish the extent, to which it could be classified as textile fibre, in this context, yarns. Four principles employed are listed as high length per diameter ratio, flexible, fineness, and length per unit weight (Kadolph, 2007). Analysing a braided banana stalk with the dimension: $3.5 \mathrm{~mm} \times 10 \mathrm{~mm}$, it is obvious that it satisfies the requirements as it is established by the essential characteristics of fibres.

\section{Physical Structure}

The banana stalk appears to be webbed and irregular but relatively glossy when dry. Fresh banana stalk is green, succulent, and juicy. However, the banana stalk is connected to the roots. Actually, the banana stem virtually intersects the leaves and the roots at the base of the plant. As matured leaves wither and get replaced by younger and fresher nodes, the older ones lose their water contents and shrink. The bright green colour turns into dark brown with patchy dark maroon and black shades intermittently placed. If overly dried, it becomes brittle and with little twists, the material simply disintegrates. In a longitudinal view, the banana stalk looks quite awkward but lengthy. It is thick layered especially, if at the base which is nearer to the roots but lighten as it approaches the real leaf. Within the inner membrane, a rather compact sheet is seen in the banana stalk and it only gets disintegrated if retted or subjected to other forms of pressure. At the cross-section, the banana stalk shows a chain of connected web with sporadic spots which are fairly circular and differ in sizes. What between is a strong mesh that forms the web sheet.

\section{Chemical Structure}

As stated earlier, the chemical composition of banana plants is as listed: carbon, hydrogen, and oxygen. Cellulose is a polymeric sugar (polysaccharide) made up of repeating 1.4-8-an hydro glucose units connected to each other by 8-ether linkages (Textile School, 2014). Textile School (2014) further asserts strong intermolecular forces between chains, coupled with the high linearity of the cellulose molecule, account for the crystalline nature of cellulosic fibres. Study of plant fibres reveals that common characteristic feature of such fibres is the chemical composition of carbon, hydrogen, and oxygen in the ratio of $\left(\mathrm{C}_{6} \mathrm{H}_{10} \mathrm{O}_{6}\right)_{n}$, where $n$ is a constant factor. It is so as $n$ remains the only varying variable that differentiates individual vegetable fibres. Sadly, $n$ could not be obtained as in 2009 when the study was carried out, Adusei-Akowuah (2009) of Seed Technology Unit, Crop Research Institute of Centre for Scientific and Industrial Research (CRI-CSIR), Kwadaso, Kumasi, indicated that apparatuses for such determinants are unavailable in Ghana. The chemical composition in the ratios presented portrays the presence of carbohydrate cellulose. Other fibres that share in this chemistry are cotton, jute, linen, and other vegetable fibres. To all intent and purpose, the existence of carbohydrate cellulose also attests to the fact that dried banana stalk is a vegetable material, better still fibre. Since banana stalk is from the banana crop, it thus, qualifies as vegetable fibre.

\section{Biological Test}

Applying experimentation, descriptive, and interpretative, this was a test done to determine the original source and the impact of man, domestic animals, bacteria, and fungi on the banana stalk. Since banana is a crop, fibres from it surely should pass for vegetable fibres. Being vegetable material also makes banana stalk predisposed to biological processes that cause attacks through fungi, moulds, bacteria, insects, rodents, and ruminants. The biological process according to Britannica Encyclopaedia is about the progressive changes in size, shape, and function during the life of an organism by which its genetic potentials (genotype) are translated 
into functioning mature systems (phenotype). Actually, the biological process occurs spontaneously in all situations but for the braid, moisture, and heat could serve as catalysts; for if wetted and kept under warm and humid conditions, facilitation of the biological process should be enhanced. They may result in loss and weakening of original materials and structures, staining, distortion, and loss of ethnographic deposits (Florian, Kronkright, \& Norton, 1990).

From the tests, it was observed that, the dried banana stalk moulds with poor odour under warm moisturizing conditions that are facilitated by fungi and bacteria. Insects, especially caterpillars, then, rodents, and ruminants may nibble the banana stalk too as they might find it edible. In excess water condition, the woody material rets. This process breaks down the woody outer membrane and later, the inner cells to get the entire material to disintegrate into minute particles and then washed away. Growth of mildew is however restricted if there is adequate aeration. Too much of heat shall cause bone dryness from shrinkage that causes the textiles to harden into brittleness and break into particles under little stress. This impedes twisting and braiding as the material disintegrates into pieces when subjected to little pressure. Where braiding is already completed before the bone dry conditions set in, the outer membrane of the braids shells off weakening the tenacity of the braids and leaves behind a coarse texture that is not so pleasant to perceive. It also reacts harshly to the skin if shuffled against the skin; the overly dried fibres/yarns could scratch the surface of the skin to form minor injuries. Excretion from man and animals as well as other bodily fluids like blood, saliva, and semen can stain the braids too.

In sum, fair amount of heat and dryness with average humidity (as in normal room temperature) is the best as it stabilizes the form of the textiles especially during twisting to make the braids. It reduces strain and stress during twisting and braiding as well for it enhances flexibility of the fibres and yarns allowing better grip and resilience of the yarns.

\section{Physical Test}

Physical test is examination to find the texture of the materials from sensual observation. It involves the use of perception from seeing, hearing, smelling, and feeling through the adoption of experimentation, descriptive, and interpretative mechanisms as well. Beyond, absorption test was used for analysing other physical features of the banana stalk braids as shown by Figures 1 and 2. The presence of corn husk was a strategy to compare effects and reactions of the variables.

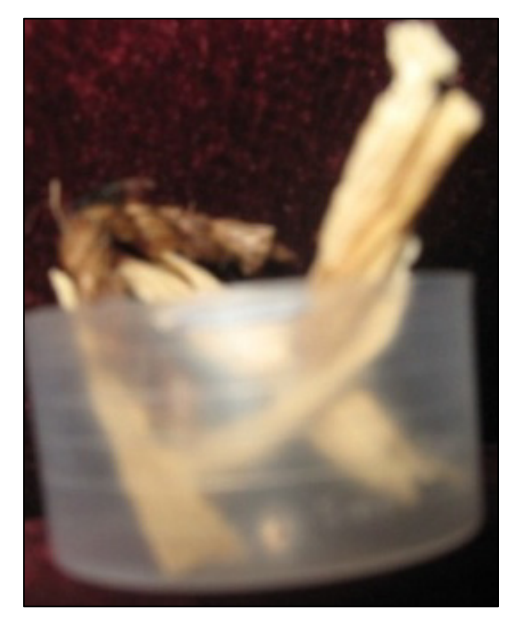

Figure 1. Receptacle of water (at room temperature) containing braided corn husk and banana stalk. 


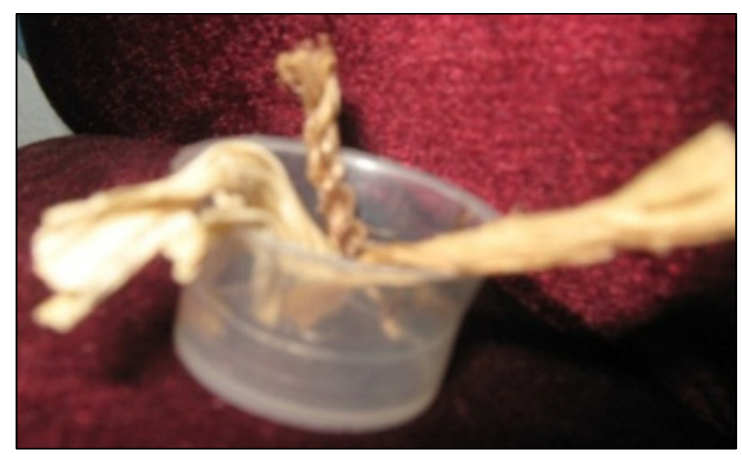

Figure 2. Braided corn husk and banana stalk in water at $100^{\circ} \mathrm{C}$.

The banana stalk is naturally brownish-grey in colour. In some instances, it appears a little pale or dark looking almost black. At the right side, it has light glossy look where as at the wrong side, it appears checked as though it must have been woven. It looks rigid and lightweight if felt with the palm and smells like dried leaves. It also smells like peeled unripe banana and could attain lengths of up to $13 \mathrm{ft}$. If wringed briskly or subjected to severe blows, it disintegrates into tiny components. In addition, when wringed, it creates sound like the pounding or treading of dry straw. Table 1 shows revelation from microscopic view of the banana stalk.

Table 1

Dried Back of Banana Stalk

\begin{tabular}{lll}
\hline Lengthwise observation & Cross-section observation & Longitudinal observation \\
\hline $\begin{array}{l}\text { Web-like but disintegrate into hair-like } \\
\text { strands when wriggled }\end{array}$ & $\begin{array}{l}\text { Thin webbed thread-like pattern with } \\
\text { uneven spots }\end{array}$ & Thick rough thread like pattern \\
\hline
\end{tabular}

Ideal dried banana stalk for textiles should appear even in weight and size. Its lengthwise structure should have uniformity so as to achieve evenness during braiding. In many instances, it is difficult to obtain ideal form from the plant, so it is advised that a pair of scissors is used to prune and shape the material before chopped into strips for twisting and braiding. If very dry, the outer membrane of the banana stalk fritters off and this process is expedited when subjected to mechanical effect like sewing with needles from both manual and electric machines. When wet, the banana stalk relaxes and unlike the corn husk becomes more extensible and elastic. It has also been deduced that the banana stalk has good affinity to colorant. The banana stalk has better affinity to natural dyes, vat dyes, and reactive dyes as well as printing paste. The glossy banana stalk is a broad sheet that has patchy shades of brown indigo and black spots intermittently spreading across.

Conclusions from the physical examinations point to the fact that the banana stalk cannot stand out as fibres with minute strands as in the case of cotton, wool, rayon, polyamide, among others. This is a webbed material that reveals its textile nature upon being converted to yarns through braiding. Both materials are very strong but coarse. These materials have inadequate elasticity thereby making them unsuitable for athletic and swimming activities for it has the tendency to impede movements of the limbs during manoeuvring. The bulky and coarse nature of the braids makes it inconvenient to be worn on the human skin, as friction evolving from the body movements shall cause shuffling that can corrode the top layer of the skin. Additional reason is based on the advice from Adusei-Akowuah (2009) who said that remnants of fertilizers, herbicides, weedicides, pesticides, and other harmful atmospheric gases could settle on the materials. According to Adusei-Akowuah (2009), since the materials have not been scoured; the tendency of these gases affecting the users of such textiles and better still, clothing could be harmful as has been experienced with some cotton derivatives. 


\section{Chemical Test}

Pertaining to the make-up of fibres, one of the most indispensable considerations is its implicit composites. Often, implicit molecules are not explicit and hence, it cannot be observed with the naked eye unless with special apparatuses. Ultimately, the explicit and implicit determination of fibres is key ingredient in identification, construction, and maintenance. Being cellulosic, banana stalk contains the listed elements of carbon, hydrogen, and oxygen. These elements have been presented earlier in the text in the ratio $-\mathrm{C}_{6} \mathrm{H}_{12} \mathrm{O}_{6}$. It is also important to note that testing to prove cellulosic characteristic of banana braid was academic as it is not necessary to prove that banana is natural and hence, findings from Florian et al. (1990, pp. 35-37) on carbohydrate, starch, sugar, fat, and general plant stain tests were employed as templates.

The essences of these tests are largely a determinant in identifying the braid and establish the extent to which the braids could be harmful or otherwise to practitioners and users of the materials. Knowledge of this is significant for forensic investigations, designing, manufacturing, showcasing, and then, care and maintenance. It equally enhances blending and doubling with other yarns for other effects especially as it stands now, the braids may not be too convenient to be worn on the human body directly for dressing. The results of the tests are indicative that the material contains carbohydrate in significant proportions. The material is also endowed with the general key elements associated with cellulosic textile materials: carbon, hydrogen, and oxygen. Collectively, these led to the conclusion that indeed the materials were vegetable textile products hence it's consideration for this work. Also, artefacts of natural origin are associated with classic appreciation and perception: likewise, this is another major reason for which the research is directed to this cause.

\section{Heat Test}

Heat could be taken for a condition where hot air is applied deliberately or accidentally. A major challenge faced by the textile materials is that, exposure to persistent heat enhances the dryness which reduces its moisture content and in the process, making its bone dry that ends up making the material brittle. If it happens before braiding, then, the slightest twist shall just end up tearing off the materials there by impeding the evenness of the subsequent braids (yarns) to be made. Already formed braids subjected to this condition loose its compatibility and consistency could break off and unravel when exposed to some fair amount of stress from abrasion. The hardness and stiffness developed by the excessive dryness could promote irritating and itching sensations as well if shuffled against the skin. Intense heat from direct exposure to sunshine with little ventilation is ideal for high rate of bone dryness. Deliberate domestic and industrial heat like that from kitchen as a result of cooking could equally create similar effect like the sun with time if it is allowed to prevail sustainably. The drying is exacerbated when positioned in concealed area and exposed to intense heat for a long time; for instance, placing behind the rear window of a completely sealed car and exposed to high sunshine.

On the contrary, if subjected to fair amount of moisturized heat as in water vapour, very dry banana stalk attains significant succulence that is ideal for twisting and braiding. This arose because of the porousness of the molecules of the materials that make it absorbent and hence, soft and relaxed. However, care ought to be taken to avoid sogginess, as that shall cause retting. Retting shall break apart the molecular structure of the materials causing them to disintegrate and hence, utter destruction of it.

\section{Tests for Other Essential Properties}

Alongside the above treated subjects, the inquest also led to revelation of significant attributes of the banana stalk braids that are obvious in conventional textile features of which most have been treated already 
and listed below. The basises for the test of other essential properties were: elasticity, extensibility, tensile strength, resilience, absorbency, dye affinity, comfortability, and reaction to dampness. The viability of a fibre is dependent on the fact that it passes as textiles, but beyond, the need to determine the ultimate use of the fibre is even more significant as it forms the basis of the value of the fibre. This is also the underlining factor for the essence of other essential characteristics. Utilizing experimentation, descriptive, and interpretative device as usual, the text revealed the extent to which the fibre is endowed with these properties to determine the adaptability and adoptability in production and regular use. Basic tests were run with apparatuses at the laboratory of the Mechanical Engineering Department of Kwame Nkrumah University of Science and technology (KNUST), Kumasi. The list below represents the key factors relevant to the project under study. It is worth to note the issue of disclaimer pointing out the fact that humidity, air pressure, and temperature were not factored in the experimentation for the simple reason was that the fibres involved are already bulky, coarse, and relatively, less fine and flexible as compared to the finer ones like cotton, silk, wool, rayon, acetate, among others. For the latter, the size and weight are so minute that, $0.001 \mathrm{~g}$ in mass or $0.001 \mathrm{~mm}$ in length could make a difference in its fineness and versatility that should reflect on collective fibre performance whereas with the banana stalk, these could be taken as infinitesimal variables. It is for this reason that those significant details were ignored. Additionally, since most of the testing were done manually and mechanically, absolute conclusions should be quite difficult to attain.

The braid was classified into three: wet (immersed into water for five minutes), wet (immersed into water for ten minutes), and then dry. Each of these three classifications was categorized further into two where braided yarns that have not been adjoined for elongation were tested separately from the joined one to find out volatility to stress and friction. By this, six tests were run. During the tests, "before and after" measurements of the diameters and lengths were determined as well as the weight at which the fibres got broken.

Tensile test. This was the first test to be undertaken aiming at deducing the feasibility and/or availability of the following essential properties in the two braids that have been itemized as: elasticity, extensibility, tensile strength, resilience, absorbency, and comfortability. For easier and expedient exercise, there was the need to have special apparatuses fixed under controlled conditions to regulate temperature, humidity, and conjecture. Since the materials involved were not as tiny as most fibres like cotton, silk, and rayon, the margin of relativity from atmospheric pressure could not greatly alter the concluding outcome of the inquest, hence, temperature and humidity of the laboratory were not controlled. Also, all the apparatuses involved were neither automated nor computerized. In that, the braids were and/or are already bulky, coarse, and limited to some extent in fineness and flexibility.

Tools, equipment, and materials adopted were veneer callipers, metal tape, a pair of shears, digital camera set, bucket, pen, sketch pad, tensile testing machine, and broad table. The materials were banana stalk braids and water at room temperature. The first was the test for braid (non-adjoined) immersed in water for five minutes. With the same conditions of the former pertaining, the observations made were - the material stretched from $100 \mathrm{~mm}$ to $123 \mathrm{~mm}$ where it also broke under the weight of $12 \mathrm{lbs}$. Next is the adjoined, which revealed a stretch of $120 \mathrm{~mm}$ from $100 \mathrm{~mm}$ that broke under the weight pressure of 9lbs. Subsequently, the non-adjoined that had been immersed in water for 10 minutes now became the focus and after conducting the test, the interesting disclosure found it stretched to $135.5 \mathrm{~mm}$ from $100 \mathrm{~mm}$ and broke at $13 \mathrm{lbs}$ from $0 \mathrm{lb}$. Similarly, the adjoined stretched from $100 \mathrm{~mm}$ to $134 \mathrm{~mm}$ and then broke at $9 \mathrm{lbs}$ upon stretching from $0 \mathrm{lb}$. The last test in this section involved dried braids of both non-adjoined and adjoined banana stalk. Upon subjection 
to pressure, the non-adjoined showed a tolerant stretch from $100 \mathrm{~mm}$ to $120 \mathrm{~mm}$ where it broke at $11 \mathrm{lbs}$. The adjoined stretched to $118 \mathrm{~mm}$ from $100 \mathrm{~mm}$ and then broke at $12 \mathrm{lbs}$ from $0 \mathrm{lb}$.

The data collated from the tests that were run have been organised and provided in Table 2 . To a large extent, banana stalk has significant resilience and stability. It is equally extensible and elastic as moisture virtually has no impact on its structure and form. Regardless of the state (dry or wet), banana stalk braid remains strong and stable indicating virtual maintenance of form. As noted earlier, findings from the test indicated further that the banana stalk braid has great tensile strength and is equally resilient when dried. It is marginally extensible and elastic thereby making it less flexible and ultimately, less comfortable effect on the skin as its drapery effect is limited.

Table 2

Data Chart for Tensile Test of Banana Stalk

\begin{tabular}{|c|c|c|c|c|c|c|c|}
\hline \multirow{2}{*}{ items } & & \multicolumn{2}{|c|}{ Diameters } & \multicolumn{2}{|l|}{ Lengths } & \multicolumn{2}{|c|}{ Breakage weights } \\
\hline & & Before & After & Before & After & Before & After \\
\hline \multirow{2}{*}{$\begin{array}{l}\text { Wet } 5 \text { min in water at room } \\
\text { temperature }\end{array}$} & Non-adjoined & $0.3 \mathrm{~cm}$ & $0.3 \mathrm{~cm}$ & $1.00 \mathrm{~cm}$ & $1.23 \mathrm{~cm}$ & $0 \mathrm{lb}$ & $12 \mathrm{lbs}$ \\
\hline & Adjoined & $0.3 \mathrm{~cm}$ & $0.3 \mathrm{~cm}$ & $1.00 \mathrm{~cm}$ & $1.22 \mathrm{~cm}$ & $0 \mathrm{lb}$ & $9 \mathrm{lbs}$ \\
\hline \multirow{2}{*}{$\begin{array}{l}\text { Wet } 10 \mathrm{~min} \text { in water at } \\
\text { room temperature }\end{array}$} & Non-adjoined & $0.3 \mathrm{~cm}$ & $0.3 \mathrm{~cm}$ & $1.00 \mathrm{~cm}$ & $1.23 \mathrm{~cm}$ & $0 \mathrm{lb}$ & $12 \mathrm{lbs}$ \\
\hline & Adjoined & $0.3 \mathrm{~cm}$ & $0.3 \mathrm{~cm}$ & $1.00 \mathrm{~cm}$ & $1.22 \mathrm{~cm}$ & $0 \mathrm{lb}$ & $9 \mathrm{lbs}$ \\
\hline \multirow{2}{*}{ Dry } & Non-adjoined & $0.3 \mathrm{~cm}$ & $0.3 \mathrm{~cm}$ & $1.00 \mathrm{~cm}$ & $1.20 \mathrm{~cm}$ & Olb & $11 \mathrm{lbs}$ \\
\hline & Adjoined & $0.3 \mathrm{~cm}$ & $0.3 \mathrm{~cm}$ & $1.00 \mathrm{~cm}$ & $1.18 \mathrm{~cm}$ & $0 \mathrm{lb}$ & $12 \mathrm{lbs}$ \\
\hline
\end{tabular}

Note. The $0.3 \mathrm{~cm}(3 \mathrm{~mm})$ length of the after diameter is approximated as infinitesimal figure differences between $0.015 \mathrm{~cm}$ and $0.035 \mathrm{~cm}$ from the before were recorded.

Absorption test. Following the tensile test, the absorption test followed. Together with the tensile test, these two broad experiments revealed vital properties relating to the other essential properties and care and maintenance. The absorption test was vital in that it was to find out the capabilities of the braids regarding the absorption or repellent of water (fluids) and dye affinity. With the conditions of the tensile test pertaining as well, the absorption test however, utilized the following: water receptacle, veneer callipers, tape measure, a pair of scissors, gas cooker, saucepan, and cup. The materials involved were braided banana stalk and water. It should be re-iterated through the disclaimer that the conditions that abounded for the previous tests applied here likewise that the laboratory temperature and humidity were not controlled and also, sensitivity of the equipment and applications were not automated and/or computerized because of the nature of the materials under review.

The banana braid of the dimension $3 \mathrm{~mm} \times 45 \mathrm{~mm}$ was immersed into water of room temperature for $10 \mathrm{~min}$. After exhaustion of the $10 \mathrm{~min}$, the banana stalk virtually maintained its form and shape through the period under review and after. Additionally, it (braid) increased in diameter to $3.3 \mathrm{~mm}$. It maintained the length but the water level dropped to $4.95 \mathrm{~mL}$. After $15 \mathrm{~min}$, the banana stalk remained as it was but the corn husk totally got dismantled immaculately. Throughout all these period, the banana remained unchanged as well as the lengths of both yarns; however, the water levels showed some interesting changes. After 15min, the banana stalk receptacle reduced by $0.10 \mathrm{~mL}$ to $4.90 \mathrm{~mL}$ signifying the extent of relative absorption of the banana stalk over the corn husk regarding immersion in water under room temperature. However, in hot water, the banana stalk absorbed more water as was with the corn husk for the $3.80 \mathrm{~mL}$ drop attested to that.

By this, it could be concluded that, warm water gets absorbed better by both braids although the corn husk is disadvantaged as the water gets it destabilized through excessive absorption which reduces the ability of the twisted strips to obtain firmer grips during braid formation. Additionally, the texture of the corn husk also 
reduces the ability of the material (twisted corn husk strips) to achieve firmer grips during braiding. Another major deduction from the experiments is that both braids have the capacity to absorb colorants as in dyes, printing pastes, and paints. Printing pastes and paints should be ideal for corn husk as dyeing processes and it may end up destroying the whole art piece. Banana stalk should not have any major problem with any of the available media but a blend with corn husk shall make the ultimate artefact vulnerable to the weakness of the corn husk. However, concentrated erratic solvents like caustic soda can ret both braids, especially the banana stalk if not well controlled. Hence, printing and/or painting should be ideal as colorant for the artefact as sogginess is virtually reduced under such circumstances (printing/or painting). The above is illustrated by the provisions in Table 3, Figures 2 and 3.

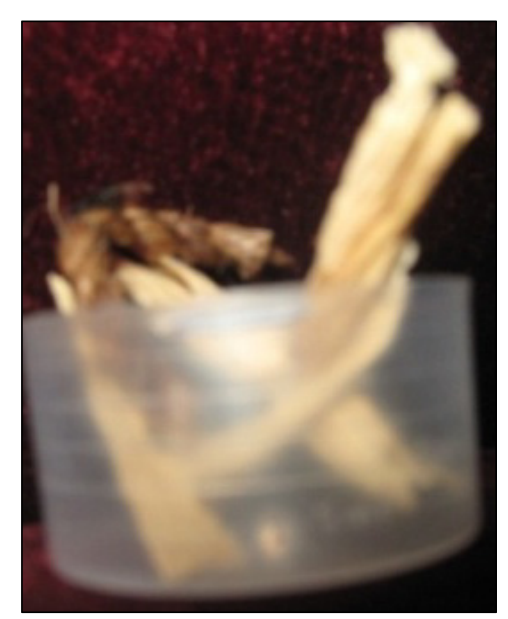

Figure 3. Braided corn husk and banana stalk in water at room temperature.

Table 3

Data Chart for Absorption Test for Banana Stalk

\begin{tabular}{|c|c|c|c|c|c|c|c|}
\hline & Diameters & & Lengths & & Time durations & Water levels & \\
\hline Temp-eratures & Before & After & Before & After & & Before & After \\
\hline $\begin{array}{l}\text { Room } \\
\text { Temp-erature }\end{array}$ & $0.3 \mathrm{~cm}$ & $0.31 \mathrm{~cm}$ & $4.5 \mathrm{~cm}$ & $4.5 \mathrm{~cm}$ & $10 \mathrm{~min}$ & $5 \mathrm{~mL}$ & $4.90 \mathrm{~mL}$ \\
\hline $100^{\circ} \mathrm{C}$ & $0.3 \mathrm{~cm}$ & $0.33 \mathrm{~cm}$ & $4.5 \mathrm{~cm}$ & $4.5 \mathrm{~cm}$ & $10 \mathrm{~min}$ & $5 \mathrm{~mL}$ & $3.80 \mathrm{~mL}$ \\
\hline
\end{tabular}

Care and maintenance. Processing of textiles and use of textile products always expose them (textiles/apparel) to filth and damage. On the contrary, some textiles may possess some elements that could react with detergents like bleaching agents that could harm practitioners and users of such materials. These assertions bring in the question of health and safety that underlines the essence of this sub-topic which is based literally on the findings of the experiments conducted. Titles to be treated are: washability (hand \& machine), bleaching, dry cleaning, pressing, drying, and damage repair.

Damage repair. Being a material for use in private and public places makes the project artefact susceptible to incidents that have the potential of changing status of the item. Should the worst happen either of two possibilities is likely to occur: repairable damage and irreparable damage? Obviously, irreparable damage should also connote that the artefact must have been spoilt completely indicative of the fact that the likely damage should have been very severe and intense. On the contrary, repairable damage is a reflection that whatever the situation, there is a chance for restoration. Possible damages that have the propensity for 
restoration have been organised according to factors indicated-laceration, fluid spillage, gathering of dust, discolouration, over-dryness, and sustained flammability. Observations made also stem from experimentation, descriptive, and interpretative.

Table 4

Apparel Care and Maintenance

\begin{tabular}{|l|l|}
\hline Symbol for system unit & Interpretation \\
\hline & No washing \\
\hline & No bleaching \\
\hline
\end{tabular}

Finishing

Finishing is a noun from finish that signifies the quality or state of being perfected. This covers all the mechanical and chemical processes employed commercially to improve the acceptability of product, except those procedures directly concerned with colouring. The objective of the various finishing processes is to make fabric from the loom or knitting frame more acceptable to the consumer thereby generating a decorative texture or appearance of the textiles and items made from it.

It is frequently necessary to carry out some preparatory treatment before the application of other finishing processes to the newly constructed fabric. Based on that, the braid was subjected to stress to observe effects and flaws and possible impact on the textiles and dress. From the inquests, it was deduced that colour adoption was plausible as the banana stalk was fairly absorbent. Printing therefore could be adopted conveniently as separate medium or joint media to add beauty and lustre likewise painting and spraying. Also, decorative stitches could be applied through varying colours for other exciting effects. Coupled with the above, trimmings and notions could be used for additional embellishment. Where necessary, varnishing becomes the last finishing medium before packaging and presentation. Varnishing in particular enhances the sheen from the various media. In the process, it increases the thickness of the braids and the stitches thereby raising the strength and quality of the banana stalk. On the contrary, varnishing should make the apparel more bulky and less porous. Chemical contents and possible health implications make it undesirable for humans to adopt the varnished costume for dressing.

\section{Conclusion}

(1) Fibre structure analysis is a key element for the determination of how far the materials could be considered as textile fibres, better still yarns, or braids.

(2) Banana stalk appears largely feasible for application in textile art and clothing. 
(3) Banana stalk could be used for industrial insulators and packaging. Cocoa beans and grains are among some major commodities with tremendous economic importance that banana stalk could package.

(4) Corn husk could do very well as textiles if mixed with banana stalk.

(5) Chemical treatment can make corn husk independent textiles but will be expensive.

\section{Reference}

Adusei-Akowuah, P. (2009). Chemical composition of cellulose textile fibres. Crop Research Institute, Kwadoso, Kumasi.

Boon, G. K. (1981). Technology transfer in fibres, textiles, and fabrics. Sijthoff \& Noordhoff, Rockville, Maryland, USA.

Florian, M. E., Kronkright, D. P., \& Norton, R. E. (1990). The conservation of artefacts made from plants and animals. The J. Paul Getty Trust.

Hijosa, C. (2016). Innovative textile technology called PINATEX ${ }^{\mathrm{TM}}$ uses pineapple leaves to create fake leather products: Sweet as vegan. Retrieved from http://www.sweetasvegan.com/innovative-textile-technology-called-pinatex-uses-pinapple-leaves-to-create-fake-leather-prod ucts/\#comment-89

Kadolph, S. J. (2007). Textiles (10th ed). New Jersey: Pearson Education Inc.

Linnenkoper, K. (2016). Alternative textiles potential in Scandinavia. Recycling International. Retrieved from $\mathrm{http} / /$ www.recyclinginternational.com/recycling-news/9565/paper-and-textiles/norway/alternative-textiles-potential-scandin avia

Quartey, P. (2006). The textile and clothing industry of Ghana. Retrieved from http://library.fes.de/pdf-files/iez/03796/10ghana.pdf

Sourcing Materials. (2014). Fiber and fabric characteristics. Retrieved from https://courses.cit.cornell.edu/cuttingedge/sourcing_matl/10sourcing.html

Steph. (2012). Eco fabric: 14 strange and amazing textile innovations. Web Ecoist. Retrieved from http://webecoist.momtastic.com/2012/11/12/eco-fabric-14-strange-and-amazing-textile-innovations/

Textile Printing Market. (2014). Fibre identification tests to identify fibre. Fibre School. Retrieved from http://www.textileschool.com/articles/68/fiber-identification-tests-to-identify-a-fibre

Textile School. $\quad$ (2014). Natural cellulose fibres. $\quad$ Retrieved from http://www.textileschool.com/articles/70/natural-cellulose-fibres-natures-own-fibres 